\title{
Spatial Creaming and Parking?: the Case of the UK Work Programme
}

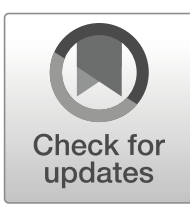

\section{A. Whitworth ${ }^{1}$}

Received: 22 August 2019 / Accepted: 21 June 2020 /

Published online: 14 July 2020

(C) The Author(s) 2020

\begin{abstract}
Public policies are inherently spatial in nature yet their geographical dimensions remain frequently underdeveloped and marginalised in policy practice and scholarship. This paper reflects critically on these common spatial blind spots, using as its case study example the UK's Work Programme employment support policy. Whilst social 'creaming' (i.e. deliberate prioritisation) and 'parking' (i.e. deliberate neglect) by providers of differently placed service users within public policies is widely acknowledged and researched, this paper introduces to the literature equivalent but neglected risks around spatial creaming and parking of differently positioned local areas. The paper's framing identifies that the Work Programme's particular treatment of place exposes areas to high risks of spatial creaming and parking. Building on these critical spatial foundations, the paper moves on to present sophisticated statistical analyses of official and comprehensive Work Programme data. These original analyses demonstrate systematic spatial inequality in outcomes and financial resource that are at the expense of already more deprived geographies and that are consistent with our spatial creaming and parking hypotheses. The paper highlights the need to consider more fully the role of place within public policy practice and scholarship.
\end{abstract}

Keywords Spatial inequality · Creaming and parking · Outcomes-based commissioning · Employment support $\cdot$ Activation $\cdot$ Spatial public policy

\section{The Neglected Spatialities of Public Policy Scholarship and Practice}

Though sometimes overlooked, public policies are inherently spatial in nature. Policy thinking - its goals, norms, approaches and outcomes - take on distinctive (EspingAndersen 1990; Arts and Gelissen 2002) and path-dependent (Pierson 1994, 2004)

A. Whitworth

adam.whitworth@sheffield.ac.uk

1 Department of Geography, University of Sheffield, Winter St, Sheffield, South Yorkshire S10 2TN, UK 
forms across different welfare contexts. So too do policy practices and the allocation of policy responsibilities across tiers of government (van Berkel et al. 2011; Peters and Pierre 2016), with powers waxing and waning between scales as policy makers seek alternative spatial solutions to new problems and priorities as they emerge (van Berkel et al. 2011). Places are also themselves frequently the object of policy interventions, and social policy interventions are always experienced by service users and frontline practitioners in, by and through the social, cultural, economic and political contexts in which they are embedded and interact (Skinner 2005; McKenzie 2015).

Public policy scholarship too is similarly enriched by a range of debates that are inherently geographical in nature. Global and comparative social policy research, for example, reflect vibrant sub-disciplinary fields of enquiry (Wood and Gough 2006; Yeates 2014), drawing out deeper understandings about policy options, dependencies and implications. Indeed, an entire sub-literature has emerged in this vein around welfare typologies (Esping-Andersen 1990; Arts and Gelissen 2002; Powell and Barrientos 2015) as well as around the circulatory transfer of policy ideas around cross-national learning networks (Peck and Theodore 2012; Obinger et al., 2012). At the level of communities and service users geography can again be seen to flow through social policy scholarship. Spatial research has also illuminated understandings of neighbourhood effects (van Ham et al. 2011) as well as the importance of spatial rhythms, journeys and external environments in shaping policy effectiveness and wider social outcomes (Wiles and Costello 2000; Skinner 2005).

However, at the same time spatial considerations occupy a peripheral place amongst policy debates and scholarship in key ways, partitioned off into discrete debates and particular sub-disciplinary fields rather than flowing through mainstream academic debates and policy practices. Conceptually, for instance, a rich seam of geography scholarship focuses on alternative conceptualisations of what space is and might be (Crang and Thrift 2000; Hubbard et al. 2002; Harvey 2006; Jessop et al. 2008; Jones 2009). This conceptual geographical richness has the potential to enhance social policy scholarship and practice but remains neglected by a partial and limited absolute view of space as boundaries on maps defining passive spatial containers to be filled up with objects (Whitworth 2019). Causally, policy interventions that are at heart seeking to tackle policy problems driven by spatial processes are frequently designed aspatially, undercutting their appropriateness and effectiveness (Massey 2001). Methodologically, a series of explicitly spatial techniques including quantitative and qualitative GIS as well as spatial statistics are routinely ignored in policy scholarship and practice, despite their ability to better understand many processes and outcomes of policy interest (Orford and Webb 2019; Harris 2019). And analytically, key spatial perspectives around geographical impacts, inequalities and clusterings are frequently overlooked within policy analyses that favour (albeit important) attention to outcomes across social groups or at geographically vast national or regional levels that conceal the majority of the spatial story within them.

Whether by absence, partiality or design, those spatial blind spots in scholarship and practice have material impacts on the ways in which policies are designed, implemented, experienced and impact. Geography shapes the areas that contracts cover and the spatial edges within which providers' services will be bounded and separated. In doing so geography importantly shapes the units at which performance will be measured, monitored and managed by commissioners and creates behavioural incentives for 
providers to act in particular ways (and not act in other ways). Crucially, these spatial decisions and impacts take place within processes of policy design and implementation irrespective of whether they are actively considered and taken explicitly or, rather, occur implicitly by default due to the neglect or partiality of geography and its implications.

In this context the present article introduces to the academic literature the notion of spatial creaming and parking. A body of international research evidence has raised consistent fears that in lightly regulated outcomes-based interventions (especially forprofit) providers respond to financial pressures and incentives by 'creaming' (i.e. deliberately prioritising) participants closer to the labour market whilst 'parking' (i.e. deliberately neglecting) those farthest from the labour market (Struyven and Steurs, 2007; Bredgaard and Larsen 2008; Considine et al. 2011; de Graaf and Sirovatka 2012). The logic to park such service users is that they have more complex (and expensive) support needs and are considered less likely by the provider to achieve payable employment outcomes, and the inverse with respect to creaming.

In contrast to this dominant discourse, we suggest that this current understanding of creaming and parking within the current academic literature and policy debate is conceptually and empirically partial in its form and specificity, pushing from view equivalent geographical risks and, potentially, geographical processes and outcomes. For although important to reveal, the current fixation with social creaming and parking alone has been accompanied by a neglect of the equivalent geographical risks and incentives around what we term spatial creaming and parking both as concept and in terms of empirical research. This neglect of geography is particularly surprising in the field of employment activation given its international experimentation with outcomesbased commissioning and calls in the literature for broader geographically rooted concepts of employability (McQuaid et al. 2005; McQuaid and Lindsay 2005) and consistent evidence that geographic context matters for employment outcomes (Turok and Webster 1998; Sunley et al. 2006; Theodore 2007).

It is this relationship between local labour market context and the likelihood of job outcomes (and hence outcome payments) in activation programmes that are at the heart of our spatial creaming and parking hypothesis. In the social creaming and parking scenario it is the systematically varying costs of support and likelihoods of payable employment outcomes or performance targets across differently positioned service users that are key to provider's incentives to cream and park different individuals. The corollary in our spatial creaming and parking hypothesis is instead their systematic variation across more and less economically buoyant local labour market contexts that shape equivalent risks and incentives for providers to cream and park different local geographies. Specifically, it is hypothesised that in less deprived local areas where job opportunities (and hence the likelihoods of payable outcomes and/or performance targets) are strongest providers face an incentive to focus their energies and resources (spatial creaming). Conversely, it is hypothesised that in more deprived local areas where job opportunities (and hence the likelihoods of payable outcomes and/or performance targets) are weakest providers face an incentive to deprioritise their energies and resources (spatial parking).

Taking as its case study example the UK's recent large-scale and aggressively quasimarketised Work Programme employment support programme, the remainder of this article shines a rare empirical spotlight on the spatial creaming and parking hypothesis 
in terms of the presence and extent of programme outcomes patterned systematically by local labour market context. To provide policy context for the later empirical analyses the next section begins by outlining the nature of the Work Programme case study and its particular spatialities.

\section{The Particular Place of Place in the UK Work Programme}

Implemented in 2011 and ceasing new referrals in 2018, the UK's Work Programme is a large scale vanguard experiment in aggressively quasi-marketized employment support. Work Programme has worked with around 2 million unemployed individuals since 2011 at a total cost of around $£ 3$ billion (DWP 2012). Work Programme delivery is structured geographically into 18 national/regional Contract Package Areas (CPAs) across England, Scotland and Wales and each CPA contains two or three large wellcapitalized 'Prime' providers who can deliver services themselves and/or sub-contract delivery through supply chains of sub-prime organisations. These CPAs are geographically large - all of Scotland is a single CPA for example - and CPAs represent the key geographical scale of Work Programme. CPAs are the geography at which commissioning and contracting took place, across which providers are required to build delivery networks and offer provision, and at which performance data are aggregated, monitored and utilized for the performance management of providers by the Department for Work and Pensions (DWP) central government commissioner.

Despite their centrality to the policy, however, the rationale for the choice of CPA as the key spatial scale within Work Programme has never been clearly articulated by DWP. Indeed, the decision to build the programme around these large regional/national CPAs spatial units faced fierce criticism from local authorities and third sector organisations for being too detached from local contexts, priorities and services and too large (financially and geographically) for third sector organisations (NCVO 2011; Taylor et al. 2017). DWP's documentation on Work Programme design and delivery arrangements offers no rationale for the CPA geography. Instead, the earlier DWPcommissioned Freud report setting out the blueprint for DWP's commissioning strategy suggests that the large geographies of these contract areas was intended to offer the large financial scale "appropriate to attract major players from around the world" (Freud 2007: 63). These providers were desired partly because they were felt by government to be of sufficient financial scale to provide the cash flow and/or to arrange the necessary private finance to bear the financial risk and payment delay of an aggressively outcomes-based payment like Work Programme. Such large capitalised providers were also argued to offer strong performance management and to minimise the contract management requirements of DWP itself given the relatively small number of large contracts that result. Interestingly, however, nowhere does the choice of CPAs as the key programme geography of Work Programme relate to them as an internally coherent or meaningful economic geography for the programme and nowhere do DWP consider the risks or implications of this spatial policy decision.

Within the Work Programme design logic outcomes rather than process was the mantra. This was in keeping with the responsible Minister's belief in using welfare markets to "unleash the creativity that a 'black box' approach to the Work Programme can offer, rather than put providers in straightjackets" (Grayling 2010). Work 
Programme deliberately offered extensive flexibility for providers over the type and frequency of support for participants. Minimal prescription over delivery existed and provider flexibility was enhanced further in practice by the combination of weak and frequently unenforceable service guarantees alongside light monitoring and oversight by the DWP below the aggregated Prime provider and CPA levels (Whitworth and Carter, 2018). Instead, the key policy lever that the DWP relied on was an unusually aggressive payment-by-results model that was heavily - and since 2014 entirely weighted towards payment for employment outcomes only (Whitworth and Carter 2018; Carter and Whitworth 2015).

DWP's Work Programme design team were well aware of these risks and in response designed a differential payment model with varying payment levels across nine payments groups intended to proxy extent of support needs and distance to labour market. DWP's hope was that this differential payments model would incentive providers to work effectively with all service users regardless of the complexity of their support needs. Unfortunately, this differential payments model has been widely evidence to be an overly crude basis on which to proxy distance to the labour market and, as a consequence, an ineffective basis on which to calibrate provider incentives (Lane et al. 2013; WPSC 2013; Carter and Whitworth 2017). Unsurprisingly given its weak performance levers (Whitworth and Carter 2018), Work Programme's live running was marred by constant political, media and academic evidence of poor quality support and, particularly, seemingly endemic creaming and parking (Newton et al. 2012; Lane et al. 2013; Meager et al. 2013; PAC 2013; WPSC 2013; Rees et al. 2014). Such creaming and parking practices are problematic at an individual level because they undermine the experiences and outcomes of already more disadvantaged service users. However, they are also problematic at the policy level. Firstly, from a fiscal perspective they undercut taxpayer value-for-money given that they imply that the DWP are systematically overpaying for outcomes. This occurs because whilst payment levels are based on averages of payment group characteristics the group in practice sees providers excluding service users with more challenging support needs. Secondly, in terms of policy objectives creaming and parking undermines DWP's stated objective in Work Programme to reduce gaps in performance outcomes between the easier- and harder-to-help groups and areas (DWP 2010).

Table 1 reflects critically on Work Programme's key geographical features and outlines the authors' perceptions of the resultant high levels of risk around spatial variability and parking that emerge from their particular configuration.

In order to offer rare empirical insights into these neglected possibilities for spatial creaming and parking within such public policy designs the remainder of the article presents original and comprehensive statistical analyses of the spatial variability in Work Programme performance and its association with local labour market context.

\section{Data and Methods}

The analyses below are based on DWP's official Work Programme statistics. These are the official, validated and comprehensive data and are available publicly via DWP's StatXplore $^{1}$ data portal. The data used include attachments (i.e. programme starts) as

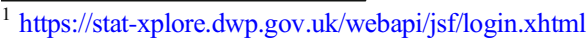


Table 1 Work Programme's key spatial features and resulting spatial risks

\begin{tabular}{|c|c|c|}
\hline & Work Programme's spatial approach & $\begin{array}{l}\text { Resultant spatial risks } \\
\text { within CPAs }\end{array}$ \\
\hline $\begin{array}{l}\text { Political ownership and } \\
\text { accountability }\end{array}$ & $\begin{array}{l}\text { - Central government only } \\
\text { - CPAs map onto no meaningful political } \\
\text { entities } \\
\text { - No roles for local authorities }\end{array}$ & High \\
\hline Policy design & $\begin{array}{l}\text { - Regional CPAs set as the key programme } \\
\text { geography } \\
\text { - Key payment-by-results varies by user type } \\
\text { but not area type } \\
\text { - 'Black box' model, weak service guarantees } \\
\text { and oversight }\end{array}$ & High \\
\hline Policy implementation & $\begin{array}{l}\text { - Central government only } \\
\text { - Performance focus at regional CPA level only } \\
\text { - Aggregated, simplified data at local authority } \\
\text { level only }\end{array}$ & High \\
\hline
\end{tabular}

well as the two ways in which Work Programme outcomes are measured and paid: initial job outcomes payments for successful transitions into employment and then monthly sustainment payments for each further month that those jobs are sustained.

A question exists around how best to capture 'performance' given these multiple outcome measures in play within the programme. The programme's payment-byresults structure itself provides the most complete and appropriate lens through which to trace this mix of performance priorities. The empirical analyses below adopt this holistic measure of performance and takes as its outcome measure average unit costs the average cash payment per service user - paid to providers in each local authority. This figure is calculated for each local authority based on the service user volumes in each area across each of the three elements of the payment profile - attachments, job outcomes and job sustainments - multiplied by the published payment values associated with each in each year of the programme (DWP 2013:5). In order to ensure comparability across areas this total cash payment value is divided by the number of programme attachments in each local authority in order to give average unit costs. As desired analytically, these earned average unit costs will vary across areas dependent upon programme performance given Work Programme's aggressve payment-by-results model.

Although a single published 'official' payment profile exists (DWP 2013) in reality Work Programme bidding and contract success was influenced by discounting from providers below those published payment values during the commissioning process (Inclusion 2011), though the extent of this discounting is not known publicly for reasons of commercial confidentiality. The empirical analyses presented below are by necessity based on the published payment profile rather than the commercially agreed payment profile that providers will have actually received. This is not considered unduly problematic for the later empirical analyses for two reasons however. Firstly there are reasons of principle. The published prices that fed into the commissioning process reflect DWP's planned policy intention on the basis of their design modelling rather than an unplanned set of commercial negotiations. Whilst DWP had worked 
extensively (if, as noted above, largely unsuccesfully) to seek to mitigate social creaming and parking in the payment model it is notable that there were no similar attempts to mitigate equivalent risks of spatial creaming and parking explicitly in that payment model or any other design features. By using the planned pricing profile acceptable to the DWP design team the empirical analyses reveal what, if any, neglected spatial implications result. Secondly there are reasons of practice. Where discounting occurred to comparable extents across CPAs then the pricing levels will be uniformly lower compared the published levels used in these empirical analyses. However, even discounting would not introduce spatial variability - this paper's key empirical interest - and hence the overall message would remain, albeit at a somewhat lower absolute level in terms of the average unit costs. There is reason to think that relatively similar levels of discounting may have occurred. All CPA commisisoning processes were highly competitive as all providers were keenly aware that these large Work Programme contracts were to be by far the largest contracts over coming years in the UK and that losing out would have serious financial and delivery implications for their organisations.

The data used cover the period from programme launch in June 2011 up until the end of December 2017, the latest date for which data are available. This covers the duration of the programme's referrals window and almost all of its delivery window. Some further minor outcomes payments not captured here would be expected beyond January 2018 but these would not affect the overall findings. The data analysed contain 1.9 million programme attachments. To maintain a clear focus the analyses concentrate only the four main Work Programme payment groups that together contain $89 \%$ of the total attachments over the period:

- Payment group 1: Jobseeker's Allowance (JSA) recipients (and Universal Credit (UC) equivalents) aged 18-24 years old. These unemployed individuals are deemed fit to work by the DWP and make up $17 \%$ of these Work Programme attachments;

- Payment group 2: JSA recipients (and UC equivalents) aged 25 years and above. This group makes up 43\% of Work Programme attachments;

- Payment group 3: JSA (and UC equivalent) Early Entrants reflect a mixed group of vulnerable benefit recipients, young people not in education, employment or training (NEETs), and individuals experiencing cycling between work and benefits (22 of the past 24 months have been in rceipt of benefits). This group comprises $17 \%$ of all attachments;

- Payment group 6: New Employment and Support Allowance (ESA) recipients (and UC equivalents) who are benefit recipients deemed by the DWP as not being fit for work due to their health condition or disability unless specific health-related supports are in place. This group makes up $12 \%$ of all attachments.

\section{Results: Placing Work Programme Outcomes in their Context}

To set the scene the left pane of Fig. 1 maps the eighteen key regional CPA geographical contract areas of the Work Programme. Inside each CPA are shown Britain's politically and administratively key local authority (municipality) geographies. These are shaded in five equally sized quintiles according to a UK-wide harmonised Index of Multiple Deprivation (Abel et al. 2016) taking account of all underlying domains in 

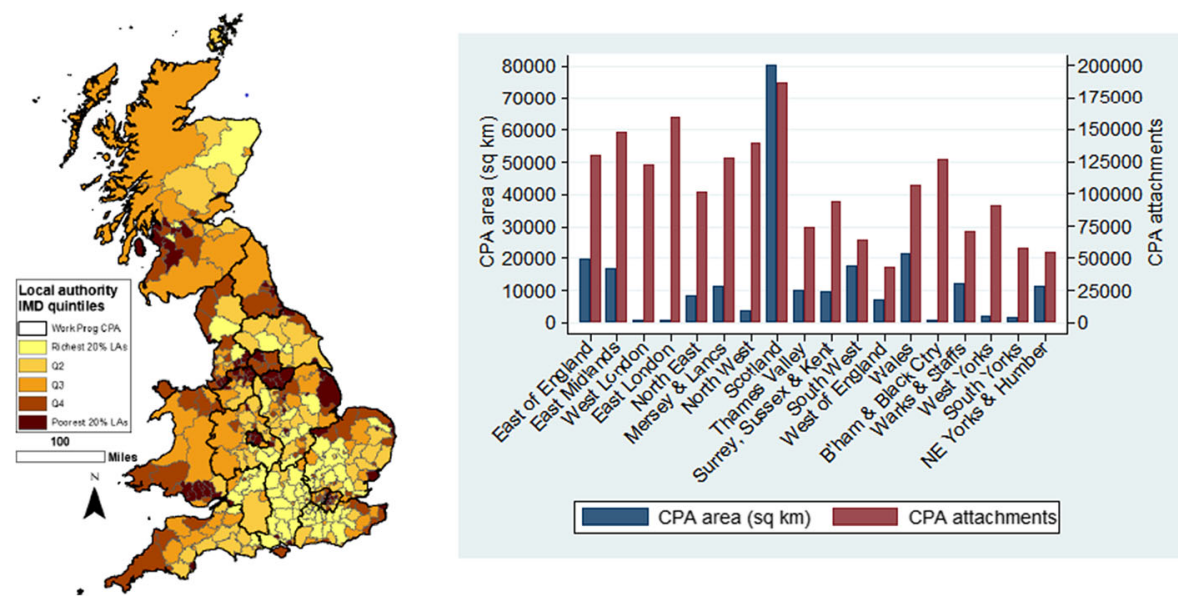

Fig. 1 Work Programme regional CPA geography (left) and size (below)

order to provide economic context for the later discussion. The spatial patterns seen are well known to those familiar with the economic geography of Great Britain. In light yellow are the $20 \%$ wealthiest local authorities in Britain that concentrate around London and its extended South East England commuter belt. In dark brown are the $20 \%$ most deprived local authorities centred around the former industrial areas of the North, Midlands and south Wales whose traditional economies have declined since the 1970s and whose on-going reincarnation as new places and increasingly service based economies has not yet fully recovered. To offer a sense of CPA's physical and financial size the right pane of Fig. 1 shows each CPA's physical area (blue bars) and its total number of Work Programme participants to Dec 2017. The nations of both Wales and Scotland present single CPA areas in the programme with Scotland by far the largest CPA territorially, providing particular challenges for its provider(s) in working with such a large geography with many areas of low population density. In contrast, CPAs containing major urban areas offer providers markedly smaller and denser CPAs but with relatively similar expected volumes and financial values.

To start to explore the spatial inequality in performance across Work Programme Fig. 2 presents the distributions of earned average unit costs for the four main payment groups across the programme's key CPA geographies. Immediately striking is that earned average unit costs are around $£ 600$ lower across all CPAs for payment group six - service users with formally recognised health conditions and disabilities. As noted above, this payment group proved to be a source of continued disappointing performance, user experiences and media and political attention for at least the first half of Work Programme's lifetime (WPSC 2013). Indeed, these earned average unit costs for payment group six are around $60 \%$ of the level that DWP intended and desired to spend on these service users (Inclusion 2014), with disappointing performance driving a vicious cycle of iteratively decreasing payments and resources for these service users within the programme. Payment group one (JSA 18-24) and payment group two (JSA $25+$ ) show earned average unit costs around $£ 1500$ as a modal value across CPAs whilst payment group three (JSA Early Entrants) shows earned average unit costs somewhat higher at around $£ 1850$ as a modal value. Also notable in the case of all four 


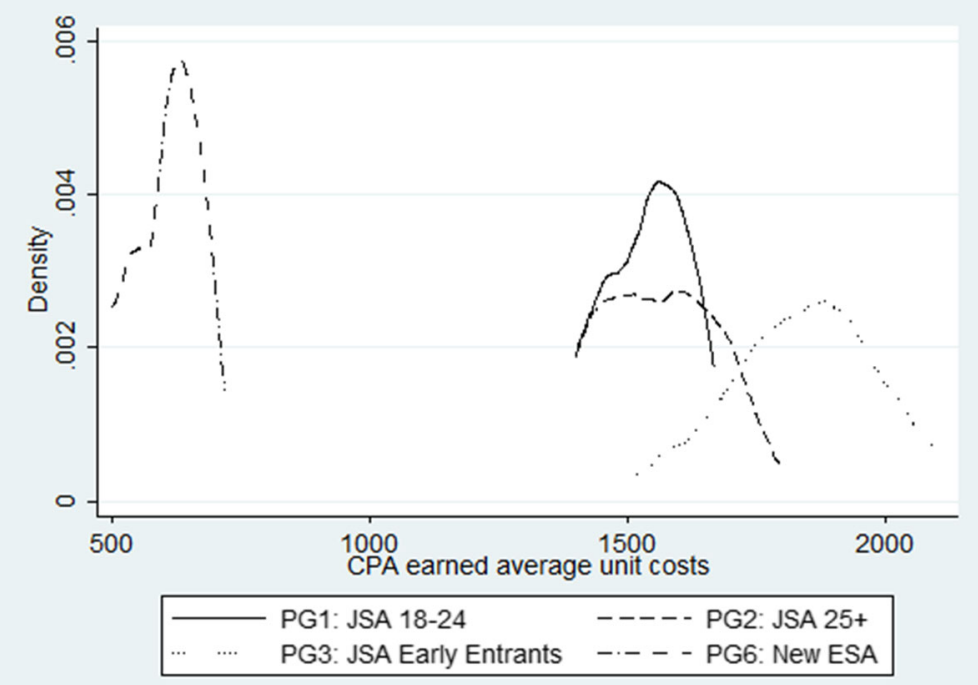

Fig. 2 Spatial variation in earned average unit costs across the CPA contract geographies

payment groups is the variability of earned average unit costs even at this high-level CPA scale. This spread covers around $£ 200$ difference in earned average unit costs across the highest and lowest CPA values for the same customer type for payment groups one and six and up to a roughly $£ 600$ difference in earned average unit costs for payment group 3. Hence, whilst geography does not feature strongly in Work Programme design and analysis the degree of spatial variability in earned outcomes certainly is material spatially.

To begin exploring empirically the neglected possibilities of spatial creaming and parking Fig. 3 presents scatterplots of the association between multi-dimensional deprivation and earned average unit costs at CPA level. Given the varying ranges in earned average unit costs across the four payment groups scales are tailored to each group and hence differ across the four charts. A clear and consistent set of visual patterns emerges. In terms of the statistical evidence, the Pearson's correlation coefficients are negative and moderately strong across all four payment groups indicating that as CPA deprivation increases the earned average unit costs tend on average to decrease. Although perhaps in contrast to the intuitive expectation that areas of greater need would receive greater resource, this seemingly counter-intuitive resource targeting is of course entirely in keeping with the pro-cyclical logic of payment-by-results policy approaches in which policies deliver better outcomes in times and places of economic buoyancy and with individuals needing least support. The inverse care law (Hart 1971) - the commonly found 'law' whereby populations with greatest health need tend to be least well served by health care systems - is by now well known in health policy debates and seems to apply equally in this quasi-marketised employment support policy.

Whilst those correlation coefficients summarise the general fit and covariance of these data they do not offer an indication of the steepness of the slope across these relationships. A series of bivariate linear regressions are therefore conducted to offer 

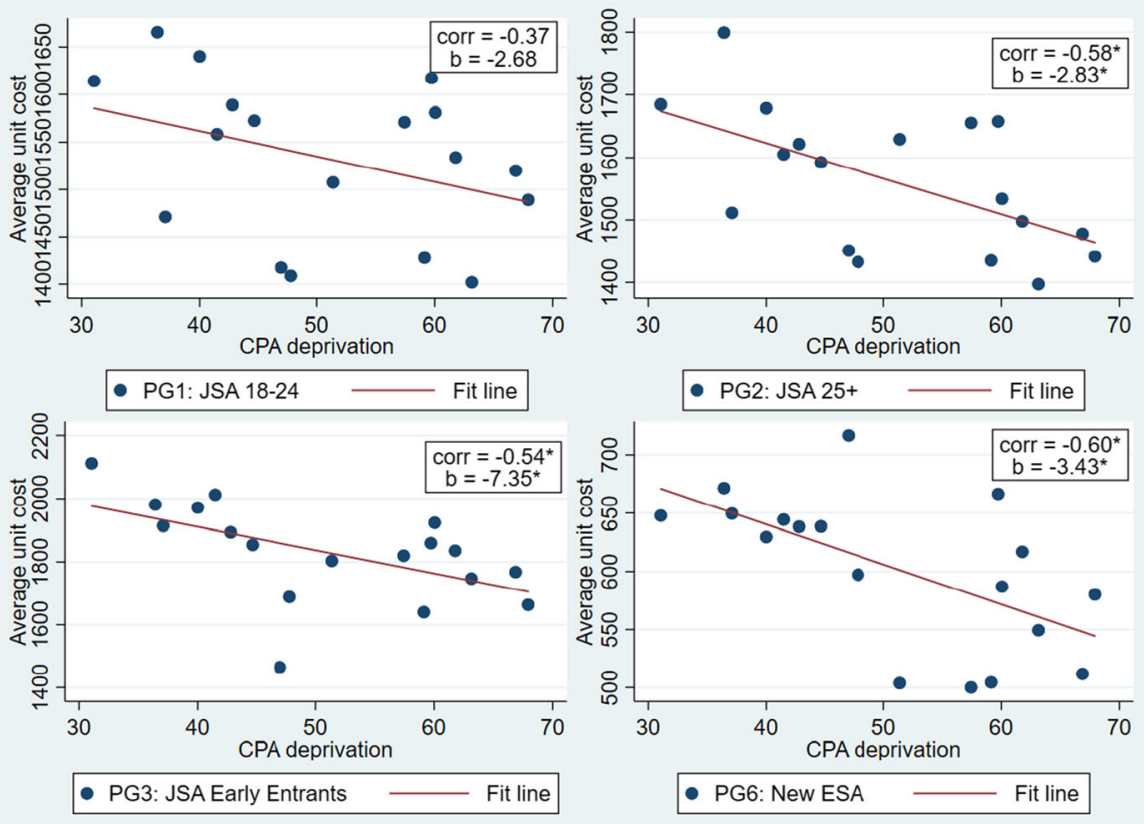

Fig. 3 Deprivation against earned average unit costs across the CPA contract geographies

these slope estimates. The aim of these statistical analyses is to simply offer indicative quantitative information about the substantive nature of these relationships and not to over-reach around their substantive implications (given that no controls are used) or their statistical significance (given the a priori expectation of detection challenges with this limited CPA sample size)(Ziliak and McCloskey 2008). For three of the four payment groups the resulting slope estimates suggest that for every one point increase in the level of deprivation in the CPA the earned average unit cost tends on average to fall by between 2.5 and 3.5 pounds sterling. With CPA deprivation scores varying between 30 and 70 points this effect would compound as deprivation gaps between wealthier and poorer CPAs grow. At the extremes of the deprivation range, for example, the roughly 40 point would equate to an earned average unit cost per service user between around $£ 100$ and $£ 140$ lower in the most deprived compared to the least deprived CPA. For the JSA Early Entry payment group the relationship is notably stronger and suggests that for every one point increase in the level of deprivation in the CPA the earned average unit cost tends on average to fall by 7.35 pounds sterling. This would equate to the most deprived CPA receiving around $£ 300$ less per Work Programme participant as an earned average unit cost compared to that seen in the least deprived CPA. For information, the presence of asterisks shows that in most cases these statistical indicators are statistically significant at the 5\% level despite the inevitably small CPA sample size.

Stepping on from these results, in terms of evidence suggestive of spatial creaming and parking these findings raise the question of whether tensions exist between aggregate CPA performance and within-CPA spatial inequalities in performance. For although statistical analyses such as these, however sophisticated, cannot prove 
causality, if deliberate spatial creaming and parking were taking place by providers in the chase for programmatically key headline CPA performance then one would expect to find two further sets of findings. Firstly, one would expect to find a pattern of higher inequality of performance across local authority areas within those CPAs alongside higher levels of aggregate CPA performance. Secondly, one would in addition expect to find that this underlying spatial inequality in constituent local authority performance would itself be structured systematically according to area's varying levels of economic buoyancy that are differentially attractive to providers in terms of the framework of geographical invectives at play in the programme.

To explore these questions Fig. 4 scatters each CPA's earned average unit costs against the standard deviation of their constituent local authority's earned average unit costs. Scales are again tailored to each payment group on these charts. Consistent with the first expectation positive associations are seen between the two across all four payment groups whereby as CPA performance increases the level of spatial inequality in performance across smaller local authority geographies within those CPAs also tends to increase. In terms of the statistical indicators, correlation coefficients are all positive and are low to moderate in strength, highest for the New ESA payment group at +0.60 . Slope estimates are again all positive and range from 0.42 to a high of 1.04 , though noting that evidence of statistical significance at the $5 \%$ level is more limited. If taken, however, such substantive relationships would imply that every additional pound in a CPA's earned average unit cost level tends on average to be associated with large increases of between $£ 0.42$ and $£ 1.04$ in the standard deviation of the constituent local authority's earned average unit costs depending on the payment group.

Figure 5 moves on to the second expectation of whether that sub-CPA spatial inequality is itself structured systematically according to local labour market context in the way that would also be hypothesised in a spatial creaming and parking hypothesis. Scales are again tailored to each payment group. Figure 5 shows that at the smaller local authority level a clear and consistent negative association is indeed found between deprivation and earned average unit costs across all four payment groups. Correlation coefficients are consistently moderate in strength and the slope estimates suggest somewhat stronger negative associations between the two than at the CPA scale, in line with the tendency of aggregation to average out some of the subtlety in any set of data. For three of the four payment groups these simple bivariate slope estimates suggest a relationship whereby a single point increase in deprivation at the local authority levels tends to associate with a five pound fall in the earned average unit cost. With a range of around 90 points on the deprivation scale this would entail an earned average unit cost in the most deprived local authority around $£ 360$ lower per service user than in the least deprived local authority. The JSA Early Entry payment group shows a somewhat larger slope estimate of -8.95 and this would equate to a difference in earned average unit costs of around $£ 800$ per service user between the most and least deprived local authority. The detection of statistical significance is inevitably simpler with this larger local authority sample size and all findings are statistically significant at the $5 \%$ level, as denoted by the asterisks.

It is clear from Fig. 5 that the relationship between earned average unit cost and local authority deprivation is downward sloping and with the slope being a function of the payment group. In this scenario formal statistical models can be utilised to test the paper's stated hypotheses formally and examine the effects of these key factors of 

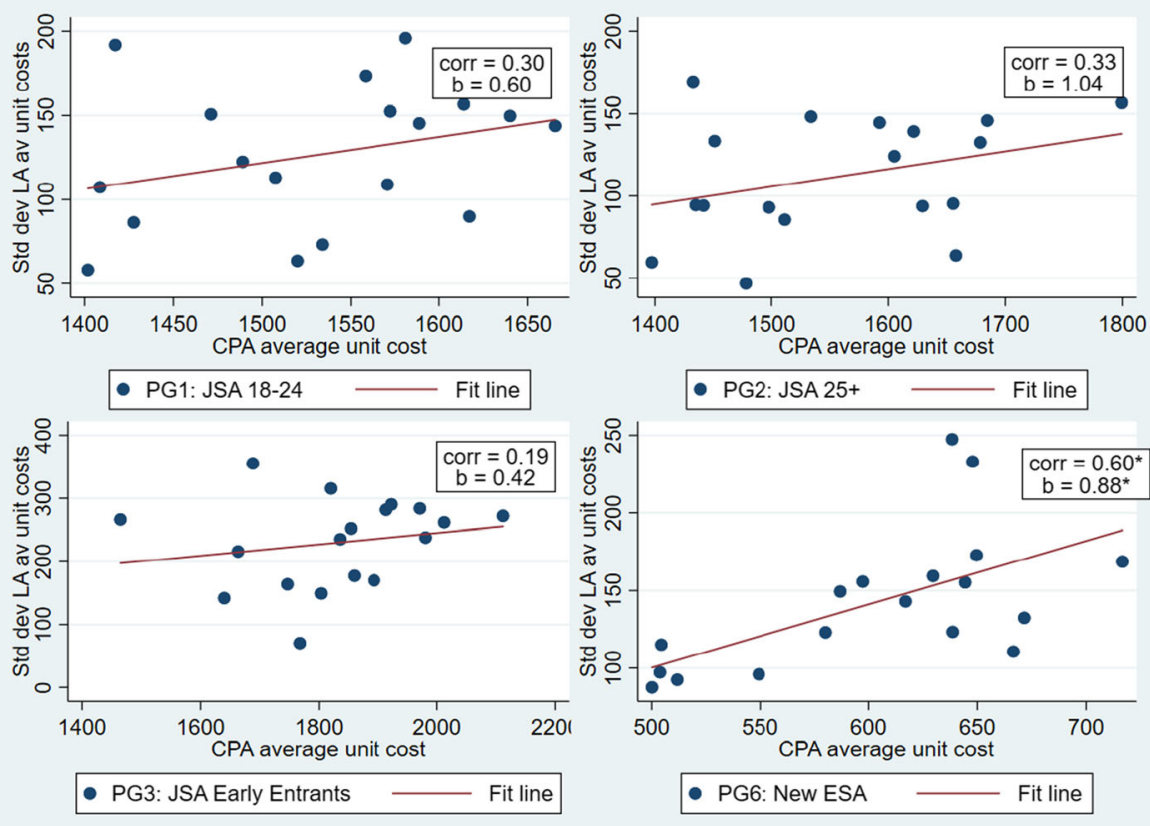

Fig. 4 Aggregate CPA performance against within-CPA spatial inequality in performance
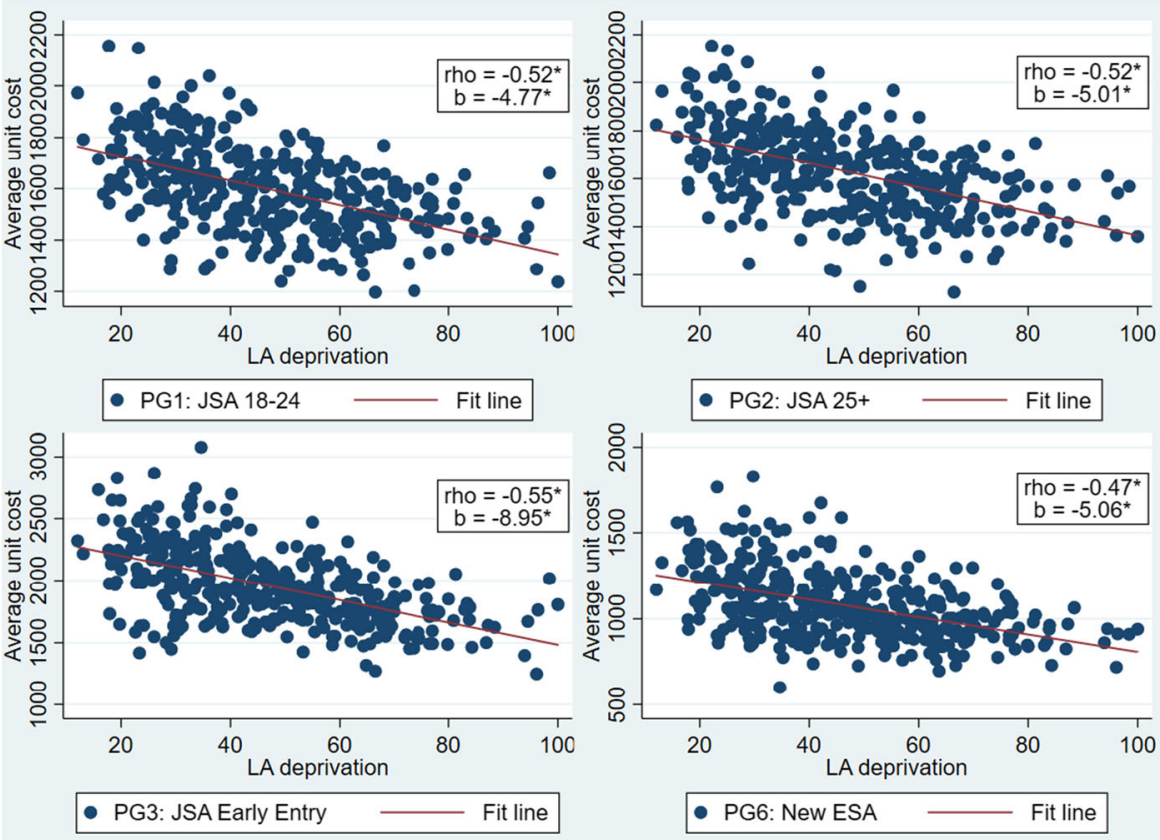

Fig. 5 Deprivation against earned average unit costs across constituent local authority areas 
interest on the earned average unit costs of each payment group across local authorities. Given that the data are hierarchically structured in nature - payment groups (level 1) nested inside local authorities (level 2) themselves nested inside contract package areas (level 3) - a three-level multilevel regression structure is explored and found in the likelihood ratio test to be a statistically superior fit to the data than the standard single level specification. This three-level multilevel linear model is therefore fitted with the 'mixed' command in Stata 16 with 1494 observations in all models.

Table 2 presents the results from these models, gradually building up their specification to explore the interplay between explanatory variables in their associations with the earned average unit costs.

Model 1 presents the simplest specification including only payment groups and the local authority harmonised Index of Multiple Deprivation (IMD) score. Controlling for deprivation, the JSA Early Entry group shows markedly higher earned average unit costs and the New ESA payment groups markedly lower earned average unit costs compared to the reference category of JSA 18-24, whilst the JSA 25+ payment group shows only slightly higher average unit costs than this reference group. The negative association between deprivation and earned average unit costs is statistically significant and estimated as equating on average to a $£ 5.40$ fall in earned average unit costs for every one point increase on the IMD scale, controlling for payment group.

Model 2 widens the scope of the analysis to include the potential for spatial spillover effects between local authority areas. This recognises the geographical possibility that local authority outcomes in public policies such as Work Programme may well be embedded within and affected by the wider regional contexts in which they are situated and interconnected. An on-going estimation challenge for multilevel models with spatial effects is the potential for bias in the estimated coefficients (Corrado and Fingleton, 2011). This estimation problem remains but any adjustment for endogeneity bias in unlikely to affect the findings materially. As such, Model 2 introduces a spatial lag of the earned average unit cost outcome variable calculated across first-order contiguous local authorities based on Queen's continuity. The findings for this spatial

Table 2 Modelling the local authority earned average unit costs

\begin{tabular}{|c|c|c|c|c|}
\hline & & Model 1 & Model 2 & Model 3 \\
\hline \multirow{4}{*}{ Payment group $(\operatorname{Ref}=$ JSA $18-24)$} & Constant & $1835.8^{* * *}$ & $990.2 * *$ & $1004.9 * *$ \\
\hline & JSA 25+ & $31.2 * *$ & 13.9 & 9.4 \\
\hline & JSA Early Entry & $361.5^{* *}$ & $161.4 * *$ & $317.7 * *$ \\
\hline & New ESA & $-522.3 * *$ & $-250.3^{* *}$ & $-264.3^{* *}$ \\
\hline Local labour market context & $\begin{array}{l}\text { Harmonised IMD score } \\
\quad(0-100 \text { scale })\end{array}$ & $-5.4 * *$ & $-5.0 * *$ & $-4.25^{* *}$ \\
\hline Spatial connectivity & $\begin{array}{l}\text { Spatial lag of earned average } \\
\text { unit cost }\end{array}$ & & $0.52 * *$ & $0.49^{* *}$ \\
\hline \multirow{3}{*}{$\begin{array}{l}\text { Interaction effect payment group \& } \\
\text { deprivation }\end{array}$} & JSA25 + *IMD & & & 0.1 \\
\hline & JSA Early Entry*IMD & & & $-3.1 * *$ \\
\hline & New ESA*IMD & & & -0.04 \\
\hline
\end{tabular}

Note: $* *$ denotes statistical significance at the $1 \%$ level or below; * denotes statistical significance at the $5 \%$ level or below 
lag variable serve to evidence the relevance of the wider regional context to Work Programme's local authority outcomes. Controlling for the other factors in Model 2, for each $£ 1$ increase in the value of the spatial lag of the outcome there is a tendency on average for a $£ 0.52$ increase in the earned average unit cost in the local authority. There is, in other words, evidence of strong and positively correlated spatial clustering of local authority earned average unit costs, even having taken account of deprivation and payment group composition in local authorities. Across the remaining variables in Model 2 the payment group dummies show marked changes in their effects once the spatial lag of the outcome is introduced. For both the JSA Early Entry and New ESA payment groups effects remain statistically significant and in the same direction but are roughly halved in their size. For the JSA 25+ payment group there no longer remains statistically significance evidence of any difference in earned average unit cots compared to the JSA 18-24 reference group. In contrast, the effect of local authority deprivation reduces only slightly in size and remains statistically significant.

Finally, Model 3 introduces an interaction effect between payment group and local authority deprivation in order to explore the possibility that the effect of deprivation varies by payment group. Only the negative interaction effect relating to the JSA Early Entry group is statistically significant. This highlights that for the JSA Early Entry group the earned average unit costs are markedly more sensitive to the level of deprivation locally (estimated to be $-7.35 * *$ ) compared to the negative association between local authority deprivation and earned average unit costs found more generally across all other payment groups (estimated at $-4.25 * *)$. Unlike earlier models, with an interaction effect present the main effects relating to deprivation and payment groups now show estimated effects when the value of the other variable in the interaction equals zero. Given that their interaction effects are statistically insignificant the main effects for the JSA 25+ and New ESA payment groups unsurprisingly remain relatively stable. The main effect for the JSA Early Entry payment group is notably larger than in Model 2 however. Compared to Model 2 without the interaction effect, this conveys a picture whereby at lower levels of deprivation the estimated earned average unit cost for the JSA Early Entry to be notably higher but then slopes drops more steeply as the level of local authority deprivation increases.

\section{Discussion}

The present paper has argued that whilst public policies are inherently spatial in nature their geographical dimensions are too often underdeveloped or pushed to the margins of policy practice and scholarship. The analyses here outline the deleterious consequences of these spatial policy blinkers for the perpetuation of existing spatial inequalities and highlight the need for deliberate and critically reflective geographical thinking within mainstream policy practice and scholarship.

The article's conceptual framing introduces for the first time in the literature to our knowledge the notion of spatial creaming and parking, a neglected but equivalent form of creaming and parking to its customary social conceptualisation. The conceptual framing then moves on to highlight a priori reasons to be concerned about the risks of spatial variability and spatial creaming and parking in Work Programme's outcomes 
and resultant resourcing given the particular and partial treatment of geography within the programme's design and live running.

Building on these critical spatial foundations, the article's original and comprehensive statistical analyses of Work Programme's geographical outcomes advance to shine a rare spotlight on the neglected spatial dimension of the creaming and parking debate. The paper's motivation is justified, with the same spatially patterned risks and experiences consistently found as seen within the dominant social creaming and parking debate. Across all four main payment groups and at both the local authority and larger CPA geographies the spatial patterns of earned average unit costs found associate strongly and systematically with deprivation. Within a multilevel statistical framework these association between deprivation and earned average unit costs remain large, negative and statistically significant even after introducing a range of contextual and compositional controls.

The practical consequence of these findings geographically is that wealthier areas see higher earned average unit costs and more deprived areas see lower earned average unit costs. The financial differences seen between more and less deprived geographies amounting to hundreds of pounds per service user. Moreover, aggregate CPA performance is found to associate positively and consistently with within-CPA variability in performance across smaller local authority geographies. This important finding lends support to the view that Work Programme providers may have been both incentivised and enabled by the programme to seek to optimise performance at the programmatically key aggregate CPA scale at least in part through deliberate spatial creaming and parking of smaller constituent geographies with more or less amenable local labour market contexts within those headline CPA geographies.

Naturally, although these findings are consistent with the expectations of our spatial creaming and parking hypothesis no quantitative analyses, however rigorous in their methods and consistent in their findings, can prove creaming and parking given that it is by its nature a causal process of deliberate provider behaviours. Future research in this neglected spatial area is required and should combine quantitative and qualitative methods in order to build the most robust and holistic evidence base possible. Particularly useful would be analyses of any systematic variation in provider estates or spend by spatial context (which DWP's shift to Open Book Accounting in the successor Work and Health Programme should now enable) as well as qualitative interviews with frontline provider staff and DWP contract managers. Given that any form of creaming and parking undercuts value-for-money as well as equity it is in the DWP's - and wider Treasury's interests - to more fully understand these programme risks and provider behaviours around spatial creaming and parking.

In terms of the quantum and wider implications of the financial sums involved, the differences in earned average unit costs seen across areas reflect not only financial rewards to providers for performance. Crucially, they also reflect public policy decisions around the level of public resource for the policy in different areas as well as the incentive for providers to operate more or less enthusiastically in different geographical contexts. That these spatial patterns in financial resources are structured systematically and inversely to deprivation fuels concerns around the role of outcomes-based policy approaches as further catalysts rather than alleviators of spatial as well as social inequality. This is perhaps contrary to intuitive public expectations - as well as stated DWP Work Programme objectives (DWP, 2010) - of the role of welfare policies as 
aiming to narrow rather than widen pre-existing gaps. Given the prevalence of outcomes-based approaches across policy domains and international contexts these counter-cyclical implications of outcomes-based policy approaches require fuller scholarly attention and debate.

Funding information The research in this article was not funded by any grant and there is no financial conflict of interest.

\section{Compliance with Ethical Standards}

Informed Consent "Informed consent was obtained from all individual participants included in the study."

Research Involving Human Participants and/or Animals "This article does not contain any studies with human participants or animals performed by any of the authors."

Conflict of Interest I can confirm that there are no conflicts of interest.

Open Access This article is licensed under a Creative Commons Attribution 4.0 International License, which permits use, sharing, adaptation, distribution and reproduction in any medium or format, as long as you give appropriate credit to the original author(s) and the source, provide a link to the Creative Commons licence, and indicate if changes were made. The images or other third party material in this article are included in the article's Creative Commons licence, unless indicated otherwise in a credit line to the material. If material is not included in the article's Creative Commons licence and your intended use is not permitted by statutory regulation or exceeds the permitted use, you will need to obtain permission directly from the copyright holder. To view a copy of this licence, visit http://creativecommons.org/licenses/by/4.0/.

\section{References}

Abel, G., Barclay, M. and Payne, R. (2016) Adjusted indices of multiple deprivation to enable comparisons within and between constituent countries of the UK including an illustration using mortality rates, BMJ Open, 6, pp1-6, e012750.

Arts, W., \& Gelissen, J. (2002). Three worlds of welfare capitalism or more? A state-of-the-art report. Journal or European Social Policy, 12(2), 137-158.

Bredgaard, T., \& Larsen, F. (2008). Quasi-markets in employment policy: Do they deliver on promises? Social Policy and Society, 7(3), 341-352.

Carter, E., \& Whitworth, A. (2015). Creaming and parking in quasi-Marketised welfare-to-Work schemes: Designed out of or designed in to the UK Work Programme? Journal of Social Policy, 44(2), 277-296.

Carter, E., \& Whitworth, A. (2017). Activation regimes and process well-being of the unemployed: Rhetoric, risk and reality of quasi-marketization in the UK Work Programme. Social Policy and Administration, 51(5), 796-816.

Considine, M., Lewis, J., \& O’Sullivan, S. (2011). Quasi-markets and service delivery flexibility following a decade of employment assistance reform in Australia. Journal of Social Policy, 40(4), 811-833.

Corrado, L. and Fingleton, B. (2011) Multilevel modelling with spatial effects. Discussion Paper, University of Strathclyde, Glasgow.

Crang, M., \& Thrift, N. (2000). Thinking space. London: Routledge.

de Graaf, W., \& Sirovatka, T. (2012). Governance reforms and their impacts on the effects of activation policies. International Journal of Sociology and Social Policy, 32(5/6), 353-363.

Department for Work and Pensions (DWP) (2010). The Work Programme invitation to tender: Specification and supporting information. Department for Work and Pensions.

Department for Work and Pensions (DWP) (2012) The Work Programme. London: DWP.

Department for Work and Pensions (DWP) (2013) Work Programme - programme costs to March 2013. London: DWP. 
Esping-Andersen, G. (1990). The three worlds of welfare capitalism. Princeton: Princeton University Press.

Freud, D. (2007). Reducing dependency, increasing opportunity: Options for the future of welfare to work. London: Department for Work and Pensions.

Grayling, C (2010) A fair approach to welfare, a speech to the Capita Welfare Reform Conference, $21^{\text {st }}$ October.

Harris, R (2019) Not just nuisance. Spatializing social statistics in Whitworth, A (ed.) Towards a spatial social policy: Bridging the gap between human geography and social policy. Bristol: Policy Press.

Hart, J. (1971). The inverse care law. The Lancet, 297(7696), 405-412.

Harvey, D (2006) Space as a keyword in Castree, N and Gregory, D (ed) Harvey: A critical reader. Wiley: Chichester.

Hubbard, P., Kitchin, R., Bartley, B., \& Fuller, D. (2002). Thinking geographically: Space, theory and contemporary human geography. London: Continuuum.

Inclusion. (2011). Work Programme results: Perform or bust. London: Inclusion.

Inclusion. (2014). Making the Work Programme work for ESA claimants: Analysis of minimum performance levels and payment models. London: Inclusion.

Jessop, B., Brenner, N., \& Jones, M. (2008). Theorizing socio-spatial relations. Environment and Planning D: Society and Space, 26(3), 389-401.

Jones, M. (2009). Phase space: Geography, relational thinking, and beyond. Progress in Human Geography, 33(4), 487-506.

Lane, P., Foster, R., Gardiner, L., Lanceley, L., \& Purvis, A. (2013). Work Programme evaluation: Procurement, supply chains and implementation of the commissioning model. London: Department for Work and Pensions.

Massey, D. (2001). Geography on the agenda. Progress in Human Geography, 25(1), 5-17.

McKenzie, L. (2015). Getting by: Estates, class and culture in austerity Britain. Bristol: Policy Press.

Meager N Newton B Foley B Sainsbury R Corden A Irving A Lane P and Weston K (2013) Work Programme evaluation: Interim Meta report. London: Department for Work and Pensions [unpublished].

McQuaid, R. W., Green, A., \& Danson, M. (2005). Introducing employability. Urban Studies, 42(2), 191195.

McQuaid, R. W., \& Lindsay, C. (2005). The concept of employability. Urban Studies, 42(2), 197-219.

NCVO. (2011). NCVO (BS 104), written evidence to The Big Society, seventeenth report of session 2010-12. London: House of Commons Public Administration Select Committee.

Newton, B., Meager, N., Bertram, C., Corden, A., George, A., Lalani, M., Metcalf, H., Rolfe, H., Sainsbury, R. and Weston, K. (2012), Work Programme evaluation: Findings from the first phase of qualitative research on programme delivery, Sheffield: Department for Work and Pensions, Research Report, No. 821.

Obinger, H., Schmitt, C., \& Starker, P. (2012). Policy diffusion and policy transfer in comparative welfare state research. Social Policy and Administration, 47(1), 111-129.

Orford, S and Webb, B. (2019) Situating social policy analysis: Possibilities from quantitative and qualitative GIS in Whitworth, a (ed.) Towards a spatial social policy: Bridging the gap between human geography and social policy. Bristol: Policy Press.

PAC, Public Accounts Committee. (2013). Department for Work and Pensions: Work Programme Outcome Statistics (no. thirty-third report of session 2012-13). London: The Stationery Office.

Peck, J., \& Theodore, N. (2012). Follow the policy: A distended case approach. Environment and Planning A: Economy and Space, 44(1), 21-30.

Peters, G., and Pierre, J. (2016). Comparative Governance: Rediscovering the functional dimension of governing. Cambridge: Cambridge University Press.

Pierson, P. (1994). Dismantling the welfare state? Reagan, Thatcher and the politics of retrenchment. Cambridge: CUP.

Pierson, P. (2004). Politics in time: History, institutions and social analysis. Princeton: Princeton University Press.

Powell, M., \& Barrientos, A. (2015). Introduction: Twenty five years of the welfare modelling business. Social Policy and Society, 14(2), 241-245.

Rees, J., Whitworth, A., \& Carter, E. (2014). Support for all in the UK Work Programme? Differential payments, same old problem. Social Policy and Administration, 48(2), 221-239.

Skinner, C (2005) Co-ordination points: A hidden factor in reconciling work and family life, Journal of Social Policy, 34(1), pp99-119, 99.

Struyven, L., \& Steurs, G. (2007). Design and redesign of a quasi-market for the reintegration of jobseekers: Empirical evidence from Australia and the Netherlands. Journal of European Social Policy, 15(3), 211229. 
Sunley, P., Martin, R., \& Nativel, C. (2006). Putting workfare in place: Local labour markets and the new Deal. Oxford: Blackwell.

Taylor, R., Damm, C., \& Rees, J. (2017). Navigating a new landscape: The third sector delivering contacted employment services. In J. Rees \& D. Mullins (Eds.), The third sector delivering public services: Developments, innovations and challenges. Bristol: Policy Press.

Theodore, N. (2007). New labour at work: Long-term unemployment and the geography of opportunity. Cambridge Journal of Economics, 31(6), 927-939.

Turok, I., \& Webster, D. (1998). The new Deal: Jeopardised by the geography of unemployment? Local Economy, 12(4), 309-328.

van Berkel, R., de Graaf, W. and Sirovatka, T. (2011) (eds) The governance of active welfare states in Europe. Basingstoke: Palgrave Macmillan.

van Ham, M., Maonly, D., Bailey, N., Simpson, L. and Maclennan, D. (eds) (2011) Neighbourhood Effects Research: New Perspectives. Dordrecht: Springer.

Whitworth, A (2019) Introduction in Whitworth, A (ed.) Towards a spatial social policy: Bridging the gap between human geography and social policy. Bristol: Policy Press.

Whitworth, A., \& Carter, E. (2018). Rescaling employment support accountability: From negative national neoliberalism to positively integrated city-region ecosystems. Environment and Planning C: Politics and Space, 36(2), 274-289.

Wiles, P and Costello, A (2000) The 'road to nowhere': The evidence for travelling criminals. Home Office: Research, Development and Statistics Directorate.

Wood, G., \& Gough, I. (2006). A comparative welfare regime approach to global social policy. World Development, 34(10), 1696-1712.

Work and Pensions Select Committee (WPSC). (2013). Can the Work Programme work for all user groups?, first report of session 2013-14. London: The Stationery Office.

Yeates, N. (Ed.). (2014). Understanding global social policy. Bristol: Policy Press.

Ziliak, S., \& McCloskey, D. (2008). The cult of statistical significance: How the standard error cost us jobs, justice and lives. Michigan: University of Michigan Press.

Publisher's Note Springer Nature remains neutral with regard to jurisdictional claims in published maps and institutional affiliations. 